\title{
Correction to: Early Second Trimester Maternal Serum Steroid-Related Biomarkers Associated with Autism Spectrum Disorder
}

\author{
Deborah A. Bilder ${ }^{1,5} \cdot$ M. Sean Esplin ${ }^{1,2} \cdot$ Hilary Coon $^{1} \cdot$ Paul Burghardt $^{3} \cdot$ Erin A. S. Clark $^{1} \cdot$ Alison Fraser $^{1,4}$. \\ Ken R. Smith ${ }^{1,4} \cdot$ Whitney Worsham ${ }^{1} \cdot$ Katlin Chappelle ${ }^{3} \cdot$ Thomas Rayner $^{1} \cdot$ Amanda V. Bakian $^{1}$
}

Published online: 3 September 2019

๑) Springer Science+Business Media, LLC, part of Springer Nature 2019

\section{Correction to: Journal of Autism and Developmental Disorders https://doi.org/10.1007/s10803-019-04162-2}

The original version of the article has been published without funding source information.

Funding This study was supported by University of Utah Neuroscience Initiative. Additional support was received from R01 AG022095 SMITH, KEN R, Early Life Conditions, Survival, and Health: A Pedigree-Based Population Study and R01 MH094400 COON, HILARY, Sequencing Autism Spectrum Disorder Extended Pedigrees.
Publisher's Note Springer Nature remains neutral with regard to jurisdictional claims in published maps and institutional affiliations.

The original article can be found online at https://doi.org/10.1007/ s10803-019-04162-2.

Deborah A. Bilder

deborah.bilder@hsc.utah.edu

University of Utah, Salt Lake City, UT 84108, USA

2 Intermountain Healthcare, Salt Lake City, UT, USA

3 Wayne State University, Detroit, MI, USA

4 Huntsman Cancer Institute, Salt Lake City, UT, USA

5 Utah Autism Research Program, University of Utah, 650 Komas Drive, Suite 206, Salt Lake City, UT 84108, USA 